\title{
Long-term Prognosis of Postinfectious Irritable Bowel Syndrome
} (Gut 2010;59:605-611)

Jae Myung Park, MD

Division of Gastroenterology, Department of Internal Medicine, The Catholic University of Korea College of Medicine, Seoul, Korea

\section{Summary}

Marshall et $\mathrm{al}^{1}$ has reported a study entitled "Eight year prognosis of postinfectious irritable bowel syndrome following waterborne bacterial dysentery" in the May issue of Gut 2010. This report was a cohort study from the population of Walkerton Health Study, of which participants were residents of Walkerton at the time of the outbreak in May 2000. They were invited for annual assessments of a postinfectious irritable bowel syndrome (PI-IBS) study at a research clinic until 2008. A modified Bowel Disease Questionnaire was used to diagnose IBS by Rome I criteria and to identify IBS subtypes. Of 4,561 Walkerton Health Study participants, 1,166 were eligible for this study (688 females, mean age 46.2 years). The prevalence of IBS among 742 eligible subjects who suffered acute gastroenteritis during the outbreak declined from $28.3 \%$ after 2-3 years from the infection to $15.4 \%$ after 8 years, but it remained significantly increased compared with controls who did not have history of acute gastroenteritis (OR, 3.12; 95\% CI, 1.99-5.04). Independent risk factors for PI-IBS at 8 years included female gender, younger age, prior anxiety/depression and fever or weight loss during the acute enteric illness. Authors have concluded that acute gastroenteritis could trigger IBS symptoms which persisted for at least 8 years, and the characteristics of the host and acute enteric illness could predict the long-term risk of PI-IBS.

\section{Comment}

It is important to study PI-IBS since its underlying mechanisms will help us understand other subtypes of IBS. Although most patients with infectious enteritis recover rapidly without any residual symptoms, some have persistent symptoms for many years and meet the criteria for a diagnosis of IBS. Prospective studies have shown the percentage of infected individuals who develop PI-IBS to vary from $3.7 \%$ to $36 \%{ }^{2}$ Present report is the follow-up of study from the Walkerton outbreak. ${ }^{3}$

This study is the largest and longest prospective community study of PI-IBS ever published. As the authors mentioned, the results can help clinicians to understand the long-term clinical features and to counsel patients on their long-term risk of PI-IBS. Over 8 years of follow-up, the overall prevalence of PI-IBS was $15.4 \%$, which was statistically higher than that of the controls. This implies that most patients with PI-IBS can be improved although a significant minority experiences symptoms which might persist for a long-term period. Therefore, assess-

Received: May 27, 2010 Revised: June 13, 2010 Accepted: June 14, 2010

(c) This is an Open Access article distributed under the terms of the Creative Commons Attribution Non-Commercial License (http://creativecommons. org/licenses/by-nc/3.0) which permits unrestricted non-commercial use, distribution, and reproduction in any medium, provided the original work is properly cited.

*Correspondence: Jae Myung Park, MD Division of Gastroenterology, Department of Internal Medicine, Seoul St. Mary's Hospital, The Catholic University of Korea College of Medicine, 505 Banpo-dong, Seocho-gu, Seoul 137-070, Korea

Financial support: None. Tel: +82-2-2258-6023, Fax: +82-2-2258-2055, E-mail: parkjerry@hanmail.net

Conflicts of interest: None. 
ment of predictors in developing PI-IBS is clinically important. In this report, risk factors for persistent symptoms after 8 years from the initial infection were female gender, younger age, prior anxiety or depression and both fever and weight loss during the acute gastroenteritis. Among these, female gender, younger age and weight loss during the acute gastroenteritis were consistent risk factors compared to the previous report of the authors. However, prior anxiety or depression was added in the risk factor. These findings suggest, as with IBS in general, the mechanism for development of PI-IBS to be explained by using a biopsychosocial model which reflects the influences from both the brain and gut. ${ }^{4}$

Authors reported an interesting finding that subtypes of PI-IBS were not stable over time. A previous study reported that $63 \%$ of cases of PI-IBS following Campylobacter jejuni-associated enteritis met the Rome II criteria for diarrhea-predominant IBS. Present study showed that more than $90 \%$ of the patients with diarrhea-predominant IBS in 2002/3 to present with constipation-predominant IBS or unsubtyped IBS in 2008. This observation suggests clinicians to treat the PI-IBS patients with their dominant symptoms.

Authors mentioned several weaknesses of this study as follows. First, only a minority of its participants had a cultureproven infection. Second, only 2,309 of the original 4,315 Walkerton Health Study participants $(53.5 \%)$ returned for reassessment in 2008. Third, authors were unable to assess rigorously some important aspects of premorbid health, such as pre- vious gastrointestinal symptoms and psychological profile. Besides these limitations, there is not much more message compared with the author's previous reports even though this paper gives valuable data with the long-term follow-up of PI-IBS. And there is no information about newly developed PI-IBS during follow-up periods.

In conclusion, this report gives important messages. Acute gastroenteritis can trigger IBS symptoms that persist for at least 8 years. Characteristics of the host and acute enteric illness can predict the long-term risk of PI-IBS. These data will help clinicians to understand the long-term clinical features of PI-IBS.

\section{References}

1. Marshall JK, Thabane M, Garg AX, Clark WF, Moayyedi P, Collins SM; Walkerton Health Study Investigators. Eight year prognosis of postinfectious irritable bowel syndrome following waterborne bacterial dysentery. Gut 2010;59:605-611.

2. Thabane M, Kottachchi DT, Marshall JK. Systematic review and meta-analysis: the incidence and prognosis of post-infectious irritable bowel syndrome. Aliment Pharmacol Ther 2007;26:535-544.

3. Marshall JK, Thabane M, Garg AX, et al. Incidence and epidemiology of irritable bowel syndrome after a large waterborne outbreak of bacterial dysentery. Gastroenterology 2006;131:445-450.

4. Drossman DA. Gastrointestinal illness and the biopsychosocial model. J Clin Gastroenterol 1996;22:252-254.

5. Dunlop SP, Jenkins D, Neal KR, Spiller RC. Relative importance of enterochromaffin cell hyperplasia, anxiety, and depression in postinfectious IBS. Gastroenterology 2003;125:1651-1659. 